\title{
Implementation and scientific evaluation of rehabilitative sports groups for prostate cancer patients: study protocol of the ProRehab Study
}

\author{
Eva M Zopf ${ }^{*}$, Moritz Braun², Stefan Machtens ${ }^{3}$, Jürgen Zumbé ${ }^{4}$, Wilhelm Bloch¹ and Freerk T Baumann ${ }^{1}$
}

\begin{abstract}
Background: Although treatment regimen have improved in the last few years, prostate cancer patients following a radical prostatectomy still experience severe disease- and treatment-related side effects, including urinary incontinence, erectile dysfunction and psychological issues. Despite high incidence rates and the common adverse effects there is a lack of supportive measures for male patients and specific physical exercise recommendations for prostate cancer patients during rehabilitation or in the aftercare are still missing.

Methods/Design: The ProRehab Project aims to establish rehabilitative sports groups particularly for prostate cancer patients and to evaluate the effects of the offered exercise program. Starting 8-12 weeks after prostatectomy or combination therapy, prostate cancer patients will exercise for 15 months within a patient preference randomized controlled trial. One exercise session will be conducted within a pre-established rehabilitative sports group, while the other will be completed independently. Patients in the control group will not participate in the intervention. The main outcomes of the study include aerobic fitness, quality of life, incontinence and erectile dysfunction.
\end{abstract}

Discussion: By combining science, practice, and public relations the first rehabilitative sports groups for prostate cancer patients in Germany have been set up and thus contribute to the care structure for prostate cancer patients. By offering a 15-month physical exercise intervention that is conducted in supervised group sessions, long-term lifestyle changes and therefore improvements in quality of life in prostate cancer patients can be expected.

Trial registration: German Clinical Trials Register DRKS00004184

Keywords: Prostate cancer, Rehabilitative sports groups, Physical activity, Exercise

\section{Background}

Despite improved treatment regimes and diagnostic methods, the consequences of a prostate cancer ( $\mathrm{PCa}$ ) disease and its medical treatment are profound. The most common side effects caused by radical prostatectomy or irradiation are urinary incontinence and erectile dysfunction [1,2]. Depending on the surgical technique, the surgeons experience, the definition of urinary incontinence, and the method of assessment, 5-74\% PCa patients experience urinary incontinence after prostate

\footnotetext{
* Correspondence: e.zopf@dshs-koeln.de

'Institute of Cardiovascular Research and Sport Medicine, Department of Molecular and Cellular Sport Medicine, German Sport University Cologne, Am Sportpark Müngersdorf 6, Cologne 50933, Germany

Full list of author information is available at the end of the article
}

resection $[3,4]$. While most patients will recover at least partially, others will have to live with an irreversible incontinence. The incidences of erectile dysfunction following radical prostatectomy have decreased in the past few years due to nerve-sparing surgical techniques. However many months or even years after surgery still over $60 \%$ of the patients complain about erectile dysfunction [5-7]. Due to the diagnosis and treatmentrelated symptoms PCa patients also experience fundamental psychological and psychosocial issues. Both disease-specific (i.e. urinary, sexual and bowel function) and general health-related quality of life (i.e. energy/ vitality and role performance) are negatively affected $[8,9]$. Over $50 \%$ of PCa patients that underwent a prostatectomy complain about distress and/or PCa-related

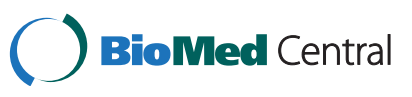


anxiety prior to an inpatient rehabilitation measure [10]. Furthermore patients receiving irradiation are at a higher risk of developing depressive symptoms or fatigue $[8,11]$. As a consequence of hospitalization and the mentioned side effects, physical function and physical activity levels of most cancer patients decrease. Approximately $30 \%$ of the adult cancer survivors exercise less after diagnosis [12]; and only $39 \%$ of the PCa survivors meet the U.S. guidelines for physical activity [13].

Studies have shown that physical activities with PCa patients are feasible, safe, and efficient. They offer a multitude of possibilities to improve patients' fitness, treatment- or disease-related side effects, well-being and quality of life during medical treatment, rehabilitation and in the aftercare [14,15]. Yet, despite the high incidence rate of $\mathrm{PCa}$ and the increasing evidence that physical activities are beneficial for PCa patients, there is a lack of supportive measures for male patients. In order to promote physical activity in cancer patients, effective strategies have to be explored, given that adopting and maintaining exercise is even more challenging for cancer patients than it is for healthy adults [16]. Since 1981, when the first official rehabilitative sports group for cancer patients was established at the German Sport University in Cologne, approximately 1000 groups were build up and provide a good care structure in Germany, however nearly $80-90 \%$ of the participants are breast cancer patients $[17,18]$.

In order to improve the care structure for PCa patients and expand the current knowledge on the efficacy of physical exercise in PCa patients in the aftercare, rehabilitative sports groups in North Rhine-Westphalia (NRW) particularly for PCa patients were established and the effects of the offered supervised exercise program will now be evaluated. The outcomes of the study include aerobic endurance performance, physical activity levels, quality of life, incontinence, erectile dysfunction, relapse-relevant blood values, and adherence. The trial is characterized by its multicentric design, exceptionally long intervention period and holistic approach. To our knowledge this is the first study with a multi-modal exercise intervention that is conducted over 15 months, begins shortly after prostatectomy, when adverse effects are most pronounced, and examines the effects on incontinence and erectile dysfunction. We therefore hypothesize that long lasting physical, psychological, and psychosocial improvements can be achieved. Finally the involvement of different institutions enables a constant exchange and a seamless transition for patients from the hospital, to the rehabilitation centre, and finally to a rehabilitative sports group near their home towns.

\section{Methods/Design}

For the following pilot project an interdisciplinary cooperation network consisting of hospitals, sports clubs, university institutions, the State Sport Association NRW, and the Cancer Society NRW was set up to establish rehabilitative sports groups particularly for $\mathrm{PCa}$ patients. In a second step a patient preference randomized controlled trial will be conducted in order to evaluate the effects of the multi-modal exercise program which will be offered to PCa patients in the newly founded rehabilitative sports groups. The study protocol has been approved by the ethics committee of the German Sport University Cologne and all patients will provide written informed consent prior to participation. While patients in the intervention group will exercise in a rehabilitative sports group for 15 months as described below (see Exercise intervention), patients in the control group will not take part in the exercise intervention.

\section{Subjects and sample size calculation}

Patients are eligible to participate in the study if they have a malignant $\mathrm{PCa}$ disease and underwent a radical prostatectomy. Inclusion and exclusion criteria are listed in Table 1.

Based on studies by Windsor et al. and Crevenna et al. a moderate improvement in physical performance after a

Table 1 Inclusion and exclusion criteria

\begin{tabular}{ll}
\hline \multicolumn{1}{c}{ Inclusion criteria } & \multicolumn{1}{c}{ Exclusion criteria } \\
\hline - malignant PCa disease & - metastatic PCa disease \\
- primary treatment involved radical prostatectomy or & $\begin{array}{l}\text { - patients scheduled to receive hormone treatment or (neo-) } \\
\text { combination therapy (radical prostatectomy + radiation) }\end{array}$ \\
- primary treatment is completed & - radiation as sole treatment \\
- primary treatment is at least 6 weeks, however no longer than 12 weeks ago & - severe cardiac disease (NYHA III-IV) \\
- written consent & - severe mental illness or chronic disease that rules out regular PA \\
& - alcohol, drug or medical abuse \\
& - insufficient German language skills \\
\hline
\end{tabular}


physical exercise intervention can be assumed when compared to a control group (effect size $\delta / \sigma=0.5$ ) $[19,20]$. In order to detect an effect with a power of $80 \%$ and a two-tailed alpha of $0.05,64$ patients need to be observed in each group. Assuming a loss-to-follow-up of $30 \%$ across the entire intervention period, a total of 182 patients $(2 \times 64 / 0.7=182)$ will need to be observed.

\section{Recruitment}

The medical assistant of the attending hospital will approach all potential study subjects and provide oral information about the intervention study. If a $\mathrm{PCa}$ patient complies with the inclusion criteria and signs a written consent approving the passing on of his contact details, the directing institution will call the patient after hospital discharge in order to provide further information. Those subjects entering the study will be invited to a preliminary conversation and for baseline measurements.

\section{Randomization}

Based on a patient preference trial, patients that refuse randomization due to a strong group preference will receive the intervention of their choice while patients who give consent to randomization will be allocated randomly [21-23]. Randomization will be conducted by the Institute of Medical Statistics, Informatics and Epidemiology at the University of Cologne. It will be achieved based on a computer-generated list and sealed envelopes will then be passed on to the corresponding institution.

\section{Exercise intervention}

After baseline measurements patients in the intervention group will exercise for 15 months in one of four rehabilitative sports groups located in a sports club closest to their home town. Physical exercise sessions will take place once a week for 60 minutes and will be financially covered by a patient's statutory health insurance

Table 2 Exercise pool of the semi-standardized multi-modal exercise program for prostate cancer patients

\begin{tabular}{|c|c|c|c|c|}
\hline & Content & $\begin{array}{c}\mathrm{N}^{\circ} \text { of } \\
\text { Exercises }\end{array}$ & Intensity & Aims \\
\hline Endurance & - Nordic walking & - & 50-70\% HRmax 11-15 RPE & $\begin{array}{l}\text { Improvements in: } \\
\text {-aerobic endurance } \\
\text {-muscle strength } \\
\text {-mobilization } \\
\text {-wellbeing }\end{array}$ \\
\hline Stretching & - stretching & 16 & $2-3 \times 10-15 \mathrm{sec}$ & $\begin{array}{l}\text { Improvements in: } \\
\text {-flexibility }\end{array}$ \\
\hline Strengthening & $\begin{array}{l}\text { - strengthening exercises incl. pelvic floor muscles } \\
\text { - resistance exercises } \\
\text { with equipment } \\
\text { or strength training machines }\end{array}$ & $\begin{array}{l}20 \\
28\end{array}$ & $\begin{array}{l}\text { 1. phase: } 1-2 \text { sets, } 8-10 \text { rep., } 30 \% \text { MVC } \\
\text { 2. phase: } 2-3 \text { sets, } 8-15 \text { rep., } \\
\text { 30-50\% MVC }\end{array}$ & $\begin{array}{l}\text { Improvements in: } \\
\text {-incontinence } \\
\text {-muscle strength } \\
\text { (esp. postural muscles) } \\
\text {-flexibility }\end{array}$ \\
\hline & -ADLs incl. pelvic floor muscles & 16 & $\begin{array}{l}\text { 3. phase: } 3 \text { sets, } 15-20 \text { rep., } \\
\text { 50-60\% MVC } \\
\text { 4. phase: } 3 \text { sets, } 12-15 \text { rep., } \\
\text { 70\% MVC }\end{array}$ & -wellbeing \\
\hline $\begin{array}{l}\text { Mixed games } \\
\text { and exercises }\end{array}$ & $\begin{array}{l}\text { - relaxation exercises } \\
\text { - breathing exercises } \\
\text { - partner exercises } \\
\text { - perception and coordination exercises } \\
\text { - cooperative games }\end{array}$ & $\begin{array}{c}8 \\
5 \\
6 \\
27 \\
8\end{array}$ & $\begin{array}{l}\text { Depending on exercise and } \\
\text { patient's condition }\end{array}$ & $\begin{array}{l}\text { Improvements in: } \\
\text {-flexibility } \\
\text {-coordination } \\
\text {-relaxation skills } \\
\text {-cognitive abilities } \\
\text { - interaction } \\
\text {-cooperation } \\
\text {-communication }\end{array}$ \\
\hline
\end{tabular}


company. Additionally subjects will be asked to exercise another 60 minutes per week home-based or within the sports club. For the home-based exercise session the type of exercise is not predefined, however patients will be asked to include the exercises they learned and report the type and duration of their activity. All group trainers will be educated by the State Sport Association NRW and receive a semi-standardized exercise program particularly for $\mathrm{PCa}$ patients. The multi-modal exercise program mainly includes aerobic and strengthening exercises, as well as games and exercises that promote flexibility, coordination, relaxation skills, cognitive abilities, interaction, cooperation and communication. Trainers will choose the training content from a pool of exercises and the training intensities will be adjusted individually based on the patient's condition and experience. Therefore new patients that join the group will slowly be introduced to the exercise program for the first few weeks. Since the intervention period is relatively long, the aim is to conduct a training that is motivational, diversified and fun. Components of the exercise program are described in Table 2. Patients in the control group will not participate in the intervention.

\section{Measurements}

Primary and secondary endpoints will be measured at three to five assessment time points in the intervention group (baseline/3 months after surgery, 6 months -, 9 months -, 12 months -, and 18 months after surgery/ post-intervention) and twice in the control group (baseline/3 months after surgery and 18 months after surgery/post-assessment). Additionally the involved hospitals will assess two measures prior to surgery for all patients. Outcome measures, assessment methods and assessment time points are depicted in Table 3.

\section{Primary and secondary endpoints}

\section{Physical fitness and physical activity levels}

In order to assess the primary endpoint, aerobic endurance, patients will perform a spiroergometry with a submaximal test protocol, which was created by a team of sport scientists and physicians. The new protocol is based on the Hollmann/Venrath protocol and was developed in order to enable a spiroergometry with $\mathrm{PCa}$ patients shortly after radical prostatectomy [24,25]. Instead of using a cycle ergometer we will use a treadmill to spare the surgical area. The initial speed of $0.8 \mathrm{~m} / \mathrm{s}$ will be increased moderately by $0.2 \mathrm{~m} / \mathrm{s}$ every 3 minutes until one of the following conditions occur: the minute ventilation or ventilation equivalent increases excessively, the ventilation equivalent reaches a value between 28 and 30, the metabolic respiratory quotient exceeds 1.0, muscular fatigue sets in, the patient feels exhausted (borg scale: $\geq 17$ ) or any complications interfere with the testing procedure. The aim is to reach lactate values of $>2.0 \mathrm{mmol} / \mathrm{l}$ blood by the end of the test, since this will be the primary endpoint of aerobic endurance performance testing. The research assistant that conducts the tests is a sport scientist who will not be involved in the training sessions and will be uninformed about the group allocation. Physical activity levels will be evaluated with the Freiburger Questionnaire of Physical Activity, a standardized questionnaire that retrospectively assesses the physical activities performed by a patient during the last 4 weeks. Based on the patients answers MET-Scores will be calculated $[26,27]$.

\section{Incontinence}

In order to examine the effects of the exercise program on urinary incontinence patients will perform a 20 -Min

Table 3 Outcome measures, assessment methods, and assessment time points of the study

\begin{tabular}{|c|c|c|c|c|c|c|c|}
\hline \multirow[t]{2}{*}{ Measures } & \multirow[t]{2}{*}{$\begin{array}{l}\text { Assessment } \\
\text { methods }\end{array}$} & \multirow[t]{2}{*}{$\begin{array}{l}\text { 1. Test } 1 \text { Day } \\
\text { Pre-OP }\end{array}$} & \multirow[t]{2}{*}{$\begin{array}{l}\text { 2. Test 6-12 Wk. } \\
\text { Post-OP }\end{array}$} & $\begin{array}{l}\text { 3. Test } 6 \text { Mo. } \\
\text { Post-OP } \\
\text { (only IG) }\end{array}$ & $\begin{array}{l}\text { 4. Test } 9 \text { Mo. } \\
\text { Post-OP } \\
\text { (only IG) }\end{array}$ & $\begin{array}{l}\text { 5. Test 12. Mo. } \\
\text { Post-OP } \\
\text { (only IG) }\end{array}$ & \multirow[t]{2}{*}{$\begin{array}{l}\text { 6. Test 18. Mo. } \\
\text { Post-OP }\end{array}$} \\
\hline & & & & \multicolumn{3}{|c|}{ 15-month exercise intervention } & \\
\hline Physical performance & $\begin{array}{l}\text { Spiroergometry } \\
\text { on treadmill }\end{array}$ & & $x$ & & $x$ & & $x$ \\
\hline Incontinence & Pad-Test & & $x$ & & $x$ & & $x$ \\
\hline $\begin{array}{l}\text { PSA, Testosterone, } \\
\text { Endostatin, VEGF }\end{array}$ & Blood Sample & & $x$ & & $x$ & & $x$ \\
\hline Quality of Life & EORTC-QLQ-C30/PR 25 & $x$ & $x$ & $x$ & $x$ & $x$ & $x$ \\
\hline Erectile Dysfunction & IIEF - Questionnaire & $x$ & $x$ & $x$ & $x$ & $x$ & $x$ \\
\hline $\begin{array}{l}\text { Physical Activity Level } \\
\text { (MET- Score) }\end{array}$ & $\begin{array}{l}\text { Freiburger Questionnaire } \\
\text { of Physical Activity }\end{array}$ & & $x$ & $x$ & $x$ & $x$ & $x$ \\
\hline Compliance & Compliance Questionnaire & & $x$ & $x$ & $x$ & $x$ & $x$ \\
\hline
\end{tabular}

EORTC-QLQ-C30/PR25: European Organization for Research and Treatment of Cancer- Quality of Life Questionnaire- Cancer/Prostate Cancer Module, IG: intervention group, IIEF: International Index of Erectile Function, MET: metabolic equivalent, Post-OP: after surgery/primary treatment, Pre-OP: prior to surgery/ primary treatment, PSA: prostate-specific antigen, VEGF: vascular endothelial growth factor. 
Pad-Test. The Pad-Test is a standardized test that objectively measures urine loss, as patients weigh their pads before and after conducting a set of incontinence-induced activities [28,29].

\section{Erectile dysfunction}

Since erectile dysfunction is a common problem following radical prostatectomy and the influence of physical activities on the erectile function of $\mathrm{PCa}$ patients is mostly unknown [30], the International Index of Erectile Function will be included as an assessment method for erectile dysfunction. The questionnaire comprises 15 questions that determine the effects that a patients erection problems have had on his sex life over the past four weeks [31,32].

Blood values In order to screen the dynamic of the carcinogenic disease, prostate-specific antigen (PSA), total testosterone, endostatin, and VEGF values will be assessed by taking blood samples. All four blood values influence the tumor environment and may be altered by physical activity [33-35].

\section{Psychological and psychosocial assessments}

To assess quality of life, patients will complete a questionnaire that was developed by the European Organization for the Research and Treatment of Cancer and has been well proven in its validity and reliability [36]. Besides the EORTC-QLQ-C30 questionnaire, a 30item scale, the PCa specific module EORTC-QLQ-PR25 with another 25 questions will be attached [37]. The assessed domains include physical function, emotional state, social interaction, global health status/quality of life, and several symptom scales.

\section{Adherence}

Patient's adherence concerning medical attendance, the physical exercise program, and further measures that are beneficial to health (e.g. cancer screening, balanced nutrition) will be assessed based on an adherence questionnaire, which has successfully been used in a study with schizophrenic patients [38], since an adequate adherence questionnaire for cancer patients in German language could not be found. The modified tool includes nine questions which can be answered on a scale of 1 (very good) to 6 (very bad). The number of exercise sessions attended will be recorded by the group trainers.

\section{Anthropometric assessments}

At baseline and final post-assessment testing height and weight will be measured in order to calculate the patients' body mass index.

\section{Discussion}

The survival rate of $\mathrm{PCa}$ patients has continuously increased in the last few years. This development has generated interest in behavior and lifestyle interventions that might further improve disease outcomes and quality of life in PCa survivors. Latest investigations show that resistance and aerobic training may improve physical fitness, fatigue, quality of life, and body composition in PCa patients [39]. These positive effects are now underlined by an observational finding that suggests that postdiagnosis physical activity is even associated with improved survival rates in PCa patients [40].

Regardless of these positive observations and the increasing evidence in the field of physical activity in $\mathrm{PCa}$ patients, a majority of patients are inactive, physicians hesitate to prescribe physical exercise, insurance coverage is insufficient, lifestyle and behavior interventions lack prioritization in the health care systems and patients are uninformed [16]. In order to improve the current situation and promote physical activity in $\mathrm{PCa}$ patients effective strategies have to be identified, including further research in the field, active involvement and briefing of oncologists, exercise therapists and insurance companies and tailored exercise programs [16].

The ProRehab project aims to create a unique and lasting exercise offer for $\mathrm{PCa}$ patients and improve the knowledge in the field of physical activity and PCa. To date the first official and certified rehabilitative sports groups particularly for PCa patients have been established in Germany. This preliminary success is based on a close cooperation between oncologists/urologists, sports clubs, university institutions, the Cancer Society NRW, the State Sport Association NRW and the statutory health insurance companies. By combining science, practice, and public relations a great contribution to the care structure for PCa patients could already be made.

We planned the described patient preference randomized controlled trial to assess the efficacy of the offered rehabilitative sports program on physical activity levels, physical fitness, incontinence, erectile dysfunction, blood values, and quality of life. According to Keogh and MacLeod (2012) group-based physical activities offer greater benefits for prostate cancer patients than homebased interventions and aerobic training should best be supplemented by resistance exercises [41]. While the positive effects of pelvic floor muscle exercises on urinary incontinence have been well proven [42], Wolin et al. now found that physically active PCa patients in general have lower incontinence rates [43]. The influence of physical activity on sexual functioning in $\mathrm{PCa}$ patients has hardly been studied [30]. We are therefore, for possibly the first time, examining the effects of a multi-modal exercise program on incontinence and erectile dysfunction in PCa patients. 
Depending on the findings of our study and future investigations the exercise program offered in the rehabilitative sports groups needs to be adjusted, since evidence based guidelines for physical activities with $\mathrm{PCa}$ patients have not yet been published. Especially randomized controlled studies with longer intervention periods ( $>1$ year) or follow-up measurements that examine the long-term effects of physical activities in PCa patients are still missing. To our knowledge this is the first study in which PCa patients exercise in a supervised setting for 15 months. By offering a physical exercise intervention that is group-based, lasts for 15 months and involves a motivational and multi-modal exercise program we are convinced that a long-term lifestyle change in PCa patients can be promoted.

\section{Abbreviations}

PCa: Prostate cancer; NRW: North Rhine-Westphalia; EORTC-QLQ-

C30: European organization for the research and treatment of cancer- quality of life questionnaire-cancer; EORTC-QLQ-PR25: European organization for the research and treatment of cancer- quality of life questionnaire- prostate cancer; MET: Metabolic equivalent; VEGF: Vascular endothelial growth factor; IG: Intervention group; IIEF: International index of erectile function; PostOP: After surgery; Pre-OP: Prior to surgery; PSA: Prostate-specific antigen; NYHA: New York heart association.

\section{Competing interests}

The authors declare that they have no competing interests.

\section{Acknowledgements}

We would like to thank the Cancer Society NRW (Krebsgesellschaft NRW e.V.), the Barmer GEK Health Insurance Company, and the State Sport Association NRW (LandesSportBund NRW) for supporting this pilot project. The project is funded by the Cancer Society NRW and the Barmer GEK Health Insurance Company. Funds are provided for personnel (EMZ, FTB), material and medical examinations.

\section{Author details}

'Institute of Cardiovascular Research and Sport Medicine, Department of Molecular and Cellular Sport Medicine, German Sport University Cologne, Am Sportpark Müngersdorf 6, Cologne 50933, Germany. ${ }^{2}$ Heilig-Geist-Hospital Cologne-Longerich, Graseggerstr. 105, Cologne-Longerich 50737, Germany. ${ }^{3}$ Marien Hospital Bergisch Gladbach, Dr.-Robert-Koch-Str. 18, Bergisch Gladbach 51465, Germany. ${ }^{4}$ Clinical Centre Leverkusen, Am Gesundheitspark 11, Leverkusen 51375, Germany.

\section{Authors' contributions}

FTB initiated the project and completed the study protocol; FTB, WB, MB, $S M, J Z$ and EMZ developed the concept of the project and FTB and WB will direct the study; MB SM and JZ will provide access to patients; EMZ and FTB will implement the protocol, acquire and analyze data; all authors read and approved the final manuscript.

Received: 26 March 2012 Accepted: 6 July 2012

Published: 24 July 2012

\section{References}

1. Frydenberg M, Stricker PD, Kaye KW: Prostate cancer diagnosis and management. Lancet 1997, 349:1681-1687.

2. Talcott JA, Rieker P, Clark JA, Propert KJ, Weeks JC, Beard CJ, Wishnow KI, Kaplan I, Loughlin KR, Richie JP, Kantoff PW: Patient-reported symptoms after primary therapy for early prostate cancer: results of a prospective cohort study. J Clin Oncol 1998, 16(1):275-283.

3. Kirschner-Hermanns R, Jakse G: Quality of life following radical prostatectomy. Crit Rev Oncol Hematol 2002, 43(2):141-151.
4. Toren P, Alibhai S, Andre M, Nesbitt M, Kalnin R, Fleschner N, Trachtenberg $\mathrm{J}$ : The effect of nerve-sparing surgery on patient-reported continence post-radical prostatectomy. Can J Urol 2009, 3(6):465-470.

5. Stanford JL, Feng Z, Hamilton AS, Gilliland FD, Stephenson RA, Eley JW, Albertsen PC, Harlan LC, Potosky AL: Urinary and Sexual Function After Radical Prostatectomy for Clinically Localized Prostate Cancer: The Prostate Cancer Outcomes Study. JAMA 2000, 283(3):354-360.

6. Schover LR, Fouladi RT, Warneke CL, Neese L, Klein EA, Zippe C, Kupellan PA: Defining sexual outcomes after treatment for localized prostate cancer. Cancer 2002, 95:1773-1785.

7. Kelovic VL, Bukovic D, Badzek S, Curic Z, Kelovic Z, Persec Z, Pavic M: Sex or Surgery- Erectile Dysfunction after Radical Treatment of Localized Prostate Cancer. Coll Antropol 2009, 33(2):529-532.

8. Namik S, Arai Y: Health-related quality of life in men with localized prostate cancer. Int J Urol 2010, 7:125-138.

9. Smith DP, King MT, Egger S, Berry MP, Stricker PD, Cozzi P, Ward J, O'Connell $\mathrm{DL}$, Armstrong BK: Quality of life three years after diagnosis of localised prostate cancer: population based cohort study. BMJ 2009, 339:b4817.

10. Mehnert A, Lehmann C, Schulte T, Koch U: Presence of Symptom Distress and Prostate Cancer-Related Anxiety in Patients at the Beginning of Cancer Rehabilitation. Onkologie 2007, 30:551-556.

11. Korfage IJ, Essink-Bot ML, Janssens ACJW, Schröder FH, de Koning HJ: Anxiety and depression after prostate cancer diagnosis and treatment: 5-year follow up. Br J Cancer 2006, 94:1093-1098.

12. Blanchard CM, Denniston MM, Baker F, Ainsworth SR, Courneya KS, Hann DM, Gesme DH, Reading D, Flynn T, Kennedy JS: Do adults change their lifestyle behaviours after a cancer diagnosis? Am J Health Behav 2003, 27(3):246-256

13. Humpel N, Iverson DC: Sleep quality, fatigue and physical activity following a cancer diagnosis. Eur J Cancer Care 2010, 19:761-768.

14. Schmitz KH, Courneya KS, Matthews CM, Demark-Wahnefried W Galvao DA, Pinto BM, Irwin ML, Wolin KY, Segal RJ, Lucia A, Schneider CM, von Gruenigen VE, Schwartz AL: Sports Medicine Roundtable on Exercise Guidelines for Cancer Survivors. Med Sci Sports Exerc 2010, 42(7):1409-1426.

15. Antonelli J, Freedland SJ, Jones LW: Exercise therapy across the prostate cancer continuum. Prostate Cancer Prostatic Dis 2009, 12:110-115.

16. Irwin ML: Physical activity interventions for cancer survivors. Br J Sports Med 2009, 43:32-38.

17. Baumann FT: Movement therapy and sport in mamma and prostate carcinoma patients: An overview. Bewegungstherapie und Gesundheitssport 2008, 24(5):182-185

18. Schüle K: The current state of physical activity and cancer therapy. Bewegungstherapie und Gesundheitssport 2006, 22(5):170-175.

19. Windsor PM, Nicol KF, Potter J: A randomized, controlled trial of aerobic exercise for treatment-related fatigue in men receiving radical external beam radiotherapy for localized prostate carcinoma. Cancer 2004, 101(3):550-557.

20. Crevenna R, Zöch C, Keilani M, Quittan M, Fialka-Moser V: Implementation of a Physical Rehabilitation Group for PostProstatectomy Urinary Incontinence Patients and its Effects on Quality of Life. Physikalische Medizin, Rehabilitationsmedizin, Kurormedizin 2003, 13(6):339-344

21. Torgerson D, Sibbald B: Understanding controlled trials: What is a patient preference trial? BMJ 1998, 316(7128):360.

22. Brewin $C R$, Bradley C: Patient preferences and randomized clinical trials. BMJ 1989, 299:313-315.

23. Adamson SJ, Bland JM, Hay EM, Johnson RE, Jones GT, Kitchener H, Klaber Moffett JA, Macfarlane GJ, MacPherson H, McLean S, Nelson L, Salisbury C, Thomas E, Tilbrook HE, Torgerson DJ: Patients' preferences within randomized trials: systematic review and patient level meta-analysis. BMJ 2008, 337:a1864.

24. Hollmann W, Venrath $\mathrm{H}$ : Spiroergometrische Standardtestmethoden. In Höchst- und Dauerleistungsfähigkeit des Sportlers. Edited by Hollmann W. Munich: Barth; 1963.

25. Blohmke M, Stumpf H, Stelzer O, Aries WD: Determination of the reliability of two submaximal loading procedures and their relationship with each other. Int Z Angew Physiol 1966, 23(1):1-11.

26. Frey I, Berg A, Grathwohl D, Keul J: Freiburger Questionnaire of physical activity- devlopment, evaluation and application. SozPraventivmed 1999, 44(2):55-64 
27. Ainsworth BE, Haskell WL, Whitt MC, Irwin ML, Swartz AM, Strath SJ, O'Brien WL, Bassett DR, Schmitz KH, Emplaincourt PO, Jacobs DR, Leon AS: Compendium of physical activities: an update of activity codes and MET intensities. Med Sci Sports Exerc 2000, 32:498-504.

28. Hahn I, Fall M: Objective quantification of stress urinary incontinence: a short, reproducible, provocative pad-test. Neurourol Urodyn 1991, 10:475-481.

29. Machold S, Olbert PJ, Hegele A, Kleinhans G, Hofmann R, Schrader AJ: Comparison of a 20-Min Pad Test with the 1-Hour Pad Test of the International Continence Society to Evaluate Post-Prostatectomy Incontinence. Urol Int 2009, 83:27-32.

30. Dahn JR, Penedo FJ, Molton I, Lopez L, Schneiderman N, Antoni MH: Physical activity and sexual functioning after radiotherapy for prostate cancer: beneficial effects for patients undergoing external beam radiotherapy. Urology 2005, 65(5):953-958

31. Rosen RC, Riley A, Wagner G, Osterloh IH, Kirkpatrick J, Mishra A: The international index of erectile dysfunction (IIEF): a multidimensional scale for assessment of erectile dysfunction. Urology 1997, 49:822-830.

32. Liatsikos EN, Assimakopoulos K, Stolzenburg JU: Quality of Life after Radical Prostaectomy. Urol Int 2008, 80:226-230.

33. Segal RJ, Reid RD, Courneya KS, Sigal RJ, Glen PK, Prud'Homme DG, Malone SC, Wells GA, Scott CG, Slovinec D'Angelo ME: Randomized Controlled Trial of Resistance or Aerobic Exercise in Men Receiving Radiation Therapy for Prostate Cancer. J Clin Oncol 2009, 27(3):344-351.

34. Brixius $K$, Schoenberger $S$, Ladage $D$, Knigge $H$, Falkowski $G$, Hellmich $M$, Graf C, Latsch J, Montiel G, Predel G, Bloch W: Long-term endurance exercise decreases antiangiogenic endostatin signalling in overweight men aged 50-60 years. Br J Sport Med 2008, 42(2):126-129.

35. Gómez A, Martinez C, Fiuza-Luces C, Herrero F, Pérez M, Madero L, Ruiz J, Lucia J, Ramirez M: Exercise training and cytokines in breast cancer survivors. Int J of Sport Med 2011, 32(6):461-467.

36. Aaronson NK, Ahmedzai S, Bergman B, Bullinger M, Cull A, Duez NJ, Filiberti A, Flechtner $\mathrm{H}$, Fleishman SB, de Haes JC: The European Organization for Research and Treatment of Cancer QLQ-C30: A quality- of-life instrument for use in international clinical trials in oncology. J Natl Cancer Inst 1993, 85:365-376

37. Van Andel G, Bottomley A, Fosså SD, Efficace F, Coens C, Guerif S, Kynaston H, Gontero P, Thalmann G, Akdas A, D'Haese S, Aaronson NK: An international field study of the EORTC QLQPR25: a questionnaire for assessing the healthrelated quality of life of patients with prostate cancer. Eur J Cancer 2008, 44:2418-2424.

38. Prinz-Kaltenborn R: Subjektive Krankheitstheorien und Compliance in der ArztPatient-Beziehung-Eine Verlaufsstudie bei schizophrenen Erkranken. PhD thesis. University of Zurich: Faculty of Arts; 2003.

39. Thorsen L, Courneya KS, Stevinson C, Fosså SD: A systematic review of physical activity in prostate cancer survivors: Outcomes, prevalence, and determinants. Support Care Cancer 2008, 16(9):987-997.

40. Kenfield SA, Stampfer MJ, Giovannucci E, Chan JM: Physical activity and survival after prostate cancer diagnosis in the health professionals follow-up study. J Clin Oncol 2011, 29(6):726-732.

41. Keogh JWL, MacLeod RD: Body Composition, Physical Fitness, Functional Performance, Quality of Life, and Fatigue Benefits of Exercise for Prostate Cancer Patients: A Systematic Review. J Pain Symptom Manage 2012, 43(1):96-110.

42. MacDonald R, Fink HA, Huckabay C, Monga M, Wilt TJ: Pelvic floor muscle training to improve urinary incontinence after radical prostatectomy: $\mathrm{A}$ systematic review of effectiveness. BJU Int 2007, 100(1):76-81.

43. Wolin KY, Luly J, Sutcliffe S, Andriole GL, Kibel AS: Risk of urinary incontinence following prostatectomy: the role of physical activity and obesity. J Urol 2010, 183(2):629-633.

doi:10.1186/1471-2407-12-312

Cite this article as: Zopf et al:: Implementation and scientific evaluation of rehabilitative sports groups for prostate cancer patients: study protocol of the ProRehab Study. BMC Cancer 2012 12:312.

\section{Submit your next manuscript to BioMed Central and take full advantage of:}

- Convenient online submission

- Thorough peer review

- No space constraints or color figure charges

- Immediate publication on acceptance

- Inclusion in PubMed, CAS, Scopus and Google Scholar

- Research which is freely available for redistribution

Submit your manuscript at www.biomedcentral.com/submit
Ciomed Central 